DR. SANNE WOLFF (Orcid ID : 0000-0002-5749-9290)

DR. ANNE-SOPHIE DARLINGTON (Orcid ID : 0000-0003-4387-7278)

Article type : Regular Article

\title{
Disparities in intensity of treatment at end-of-life among children according to the underlying
} cause of death

\section{Short title: High intensity treatment at children's end-of-life}

* S Wolff ${ }^{1,2}$, C Christiansen², S Johnsen ${ }^{3}, \mathrm{H} \mathrm{Schroeder}^{4}$, A Darlington $^{5}$, MA Neergaard ${ }^{1}$

${ }^{1}$ Palliative Care Unit, Department of Oncology, Aarhus University Hospital, Aarhus, Denmark;

${ }^{2}$ Department of Clinical Epidemiology, Aarhus University, Aarhus, Denmark; ${ }^{3}$ Danish Center for

Clinical Health Services Research, Department of Clinical Medicine, Aalborg University, Aalborg, Denmark; ${ }^{4}$ Department of Paediatrics and Adolescent Medicine, Aarhus University Hospital, Aarhus, Denmark; ${ }^{5}$ University of Southampton, Southampton, United Kingdom

Corresponding author: S Wolff, Department of Oncology, Aarhus University Hospital, Palle JuulJensens Blvd 99, 8200 Aarhus N, Denmark, +4527581134, [sanwol@rm.dk]

This article has been accepted for publication and undergone full peer review but has not been through the copyediting, typesetting, pagination and proofreading process, which may lead to differences between this version and the Version of Record. Please cite this article as doi: 10.1111/APA. 15713

This article is protected by copyright. All rights reserved 


\begin{abstract}
S Wolff, C Christiansen, S Johnsen, H Schroeder, A Darlington, MA Neergaard. Disparities in intensity of treatment at end-of-life among children according to the underlying cause of death.
\end{abstract}

\title{
Aim
}

To compare indicators of high intensity treatment at end-of-life (HI-EOL) among children according to causes of death.

\section{Methods}

We conducted a nationwide registry study in Denmark among 938 children of 1-17 years of age who died from natural causes from 2006 to 2016. We identified and compared indicators of HI-EOL within the last month of life across diagnoses. Indicators were hospital admissions, days in hospital, intensive care unit admission, mechanical ventilation, and hospital death.

\section{Results}

Proportions of each indicator of HI-EOL ranged from $27 \%$ to $75 \%$. The most common indicators were hospital death (75\%) and ICU admission (39\%). Compared to children with solid tumours, children with non-cancerous conditions had an adjusted odds ratio of 3.5 (95\% CI 2.1-5.9) of having $\geq 3$ indicators of HI-EOL within the last month of life and children with haematological cancer had an odds ratio of 11.8 (95\% CI 6.1-23.0).

\section{Conclusion}

The underlying diagnosis was strongly associated with HI-EOL. Children who died from solid tumours experienced substantially less intensive treatment than both children with haematological cancer and non-cancerous conditions did. Across non-cancerous diagnoses, the intensity of treatment appeared consistent, which may indicate, that the awareness of palliative care is higher among oncologists than within other paediatric fields.

This article is protected by copyright. All rights reserved 

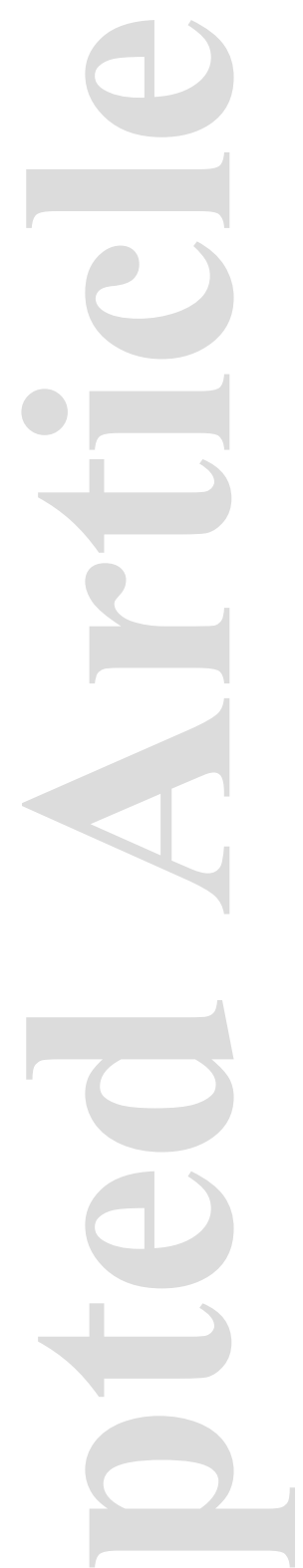

This article is protected by copyright. All rights reserved 


\section{Keynotes:}

- To determine the associations between diagnoses and the intensity of treatment at end-of-life among children, we compared indicators of high intensity treatment across underlying causes of death.

- Children who died from solid tumours experienced substantially less intensive treatment than both children with non-cancerous conditions and children with haematological cancers.

- This demonstrates a need to distinguish between cancer types and to extend paediatric end-oflife research beyond the field of oncology.

Keywords: children; end-of-life; palliative care; place of death; treatment intensity

This article is protected by copyright. All rights reserved 


\section{INTRODUCTION}

In most children suffering from a life-threatening disease, the primary goal is to cure the disease. However, it is important for the treating professionals to prepare the child and family for a potentially terminal course of the disease and to be able to balance the hope for a cure, palliative care and preparations for potential demise (1).

Medical technological advances continuously improve survival rates and the possibilities for life prolonging treatment. Thus, the line between a potential cure and terminal illness can be difficult to determine. Hence, high-intensity treatment may in some cases be continued beyond benefit and could cause unnecessary suffering for the child. Moreover, the family may be deprived of quality time and to peacefully part with the child (2).

High-intensity treatment at end-of-life (HI-EOL) among adults has been studied extensively (3). The literature offers varying definitions of HI-EOL, comprising quantifiable measures ranging from hours to months of hospitalisation and life-sustaining or life-prolonging treatment during the last period of life (3). Commonly reported measures are admissions to hospitals, emergency departments and intensive care units (ICU), mechanical ventilation, cardiopulmonary resuscitation (CPR), intravenous chemotherapy, and in-hospital death.

Each of these actions may be appropriate in cases with an expected chance of survival or prolonging of life. However, research on HI-EOL in adults suggests that disease-controlling treatments are prioritised at the expense of palliative care and potential relief of symptoms, pain and mental distress (4).

Few studies have investigated paediatric EOL trajectories; to our knowledge, there are six large scale studies investigating HI-EOL among children with cancer; one from Korea, Canada, US and France, respectively and two from Taiwan (5-10). Two studies were conducted among children with a variety of complex chronic conditions, both from the US $(11,12)$. These studies showed, that the majority of children were hospitalized and treated intensively at end of life, although the rates varied extensively between studies. The intensity of treatment was associated with demographic factors such as low socioeconomic status, ethnicity and younger age of the child $(5-10,12)$ and one study reported, that

This article is protected by copyright. All rights reserved 
children were treated with higher intensity in private hospitals compared to public (5). Furthermore, the intensity of hospitalization and cancer-directed therapies at EOL varied considerably across different cancer types $(7,8)$ and correspondingly, disparities were seen in the patterns of EOL treatment among children with other complex chronic conditions $(11,12)$. We have previously conducted a systematic review investigating the predictors of place of death among children. This review showed that the odds of dying at home were twice as high among children with cancer compared to children with non-cancerous conditions (13). Understanding how treatment trajectories differ between diagnoses and extending this knowledge beyond paediatric oncology may contribute to illuminate whether targeted efforts are needed to ensure optimal EOL care for every dying child. The aim of this study was to compare frequencies of indicators of HI-EOL among children according to the underlying causes of death.

\section{PATIENTS AND METHODS}

We conducted a nationwide registry study based on routinely collected data in a cohort of children who died between 1 January 2006 and 31 December 2016 in Denmark.

\section{Setting}

In Denmark, the number of inhabitants was approximately 5.5 million during the study period (14). The Danish healthcare system is primarily tax-financed and medical care is free of charge for all citizens (15). A unique 10-digit civil registration number is assigned to all Danish citizens upon birth or immigration; this number makes it possible to collect and link data across national registries.

There is currently two paediatric hospices in Denmark. The hospices opened in 2015 and 2020, respectively, and each hospice has room for four families (16). Outgoing paediatric multidisciplinary palliative care teams in each of the five Danish regions were established between December 2015 and June 2017 (17). Before 2015, the Danish healthcare system offered no formalised paediatric palliative care.

This article is protected by copyright. All rights reserved 


\section{Population}

We included children of 1-17 years of age who died from natural causes between 1 January 2006 and 31 December 2016.

Children below the age of one year were excluded due to major dissimilarities in the aetiology of the underlying causes of death and thus different needs for monitoring and healthcare compared with older children. We did not include children who died as a result of accidents, violence or suicide because the patterns of end-of-life trajectories would presumably be different with less potential for palliative care and home death compared to children with chronic conditions.

Data from multiple national population registries were linked using the unique 10-digit civil registration number.

The study population was identified through death certificate data retrieved from the Danish National Register of Causes of Death, a register comprising information on underlying, immediate and contributing causes of death along with the date and place of death, reported by the doctor certifying the death (18).

\section{HI-EOL}

Indicators of HI-EOL were adapted from Earle et al who determined indicators of HI-EOL among adults and stated that a high number of emergency room visits, inpatient hospital admissions, and days spent in the ICU near the end of life may indicate poor-quality care (19). The indicators were measured within the last 30 days of life and denominators were determined to ensure consistency with and comparability to previous studies of HI-EOL among children $(6-8,11,12,20)$ and based on data available from the Danish National Registry of Patients (DNRP). The length of hospital stay, although not among the indicators suggested by Earle et al, has been reported in multiple previous studies among children and was thus included among indicators of HI-EOL in this study $(11,20,21)$.

This article is protected by copyright. All rights reserved 
The indicators of HI-EOL that were identified by earlier studies were: two or more hospital admissions, 14 or more days spent in hospital, any ICU admission, any mechanical ventilation within the last 30 days of life, and hospital death.

Dates of hospital admission and discharge were identified through the DNRP and used to determine number of hospital admissions as well as number of days spent in hospital within the last 30 days of life. The entire period was considered as one single hospital admission if a patient was transferred to another department or hospital during an admission.

Place of death was determined from death certificate data and divided into hospital death or home death. Death outside hospital was regarded as home death as there were no children's hospices in Denmark before 2015. Information on place of death was missing in 40 cases (4.3\%). In these cases, place of death was determined based on hospital admission status on the date of death in the death register, assuming that when the last hospital admission included the date of death, the child had died at hospital. Children with no hospital admission on the date of death were determined as dying at home. To validate this definition, we compared hospital admission status to place of death in nonmissing cases; congruence was $90 \%$.

\section{Cause of death}

Diagnoses were classified according to the International Classification of Diseases, ICD-10 code stated as the underlying cause of death in the Danish Register of Causes of Death and grouped into solid tumour (including brain tumour), haematological cancer, congenital and genetic conditions, infectious and immunological conditions, endocrinological and metabolic conditions, neuromuscular conditions, cardiovascular conditions, respiratory conditions, other causes, and unknown causes of death. Deaths with missing information on cause of death were registered in the death register as unknown cause of death, code R990. Detailed information on the categorisation of diagnoses is available in Appendix S1.

\section{Statistical analysis}

This article is protected by copyright. All rights reserved 
We described the distribution of demographics, diagnoses and indicators of HI-EOL using prevalence proportion ratios. Univariable and multivariable logistic regression models were constructed to determine the prevalence odds ratios (ORs) between cause of death diagnoses and each indicator of HI-EOL. We chose non-haematological cancer as the reference group as this group has been used as reference group in previous studies of EOL in children $(7,8)$. Based on these indicators, we composed composite outcomes comprising the number of positive intensity indicators for each patient. We compared the odds of having any intensity indicator and subsequently the adjusted odds of having two or more and three or more intensity indicators, respectively. Associations were presented as adjusted prevalence ORs with 95\% confidence intervals (CI). Year of death, age at death and gender were included in multivariable analyses.

The analyses were performed using STATA software (StataCorp. 2017. Stata Statistical Software: Release 15. College Station, TX: StataCorp LLC).

\section{Approval}

The study was approved by the Danish Data Protection Agency (record number 2015-57-0002, Aarhus University record number 2016-051-000001/977). All data were stored at and managed by Statistics Denmark, a governmental organisation under the Ministry for Economic and Interior Affairs. According to Danish law, non-interventional registry-based studies without patient contact do not require ethical approval.

\section{RESULTS}

\section{Study population characteristics}

In Denmark, 3,814 children died in the 11-year study period from 2006 and 2016. We excluded 2,414 children who died within the first year of life and 462 who died from non-natural causes (accidents, violence or suicides). Thus, the final study population comprised 938 children at the age of 1-17 years 
who died from natural causes. Demographic characteristics, indicators of HI-EOL and place of death are listed according to underlying causes of death in Table 1.

A slight majority of deaths occurred among boys (55\%). The group of children at age 1-4 years comprised $40 \%$ of the population. The median age at death was 8.5 years within the total population (interquartile range (IQR) 3.1-14.4), but it varied considerably between diagnoses, ranging from 3.8 years (endocrinological and metabolic conditions (IQR 2.3-11.1) to 10.9 years (haematological cancers (IQR 7.5-14.4)).

The most frequent underlying causes of death were neuromuscular conditions (18\%), solid tumours $(17 \%)$ as well as congenital and genetic conditions (16\%) (Table 1).

\section{HI-EOL}

All of the indicators of HI-EOL were commonly experienced within the last month of life (Table 1). The vast majority (77\%) of the population were registered with at least one intensity indicator, and $29 \%$ had three or more indicators. Children who died from haematological cancers had three-fold increased odds of having one or more indicators of HI-EOL within the last 30 days of life (adjusted OR 3.3; 95\% CI 1.6-6.9) and 12-fold odds of experiencing three or more indicators, compared to children with solid tumours. Among children with non-cancerous conditions, the rates of having experienced one or more indicators of HI-EOL were similar across diagnoses, ranging from 73\%$82 \%$, except for the group with cardiovascular conditions. In the latter group, the rate of having one or more indicators of HI-EOL was $88 \%$ and the adjusted odds ratio was 3.5 (CI 1.6-8.0) compared to children with non-haematological cancer.

Proportions of each indicator ranged from $27 \%$ to $75 \%$ within the total population; the most common indicators of HI-EOL were hospital death (75\%) and ICU admission (39\%).

The vast majority of the children (76\%) had been admitted to hospital at least once within the last 30 days of life (data not shown), and 30\% had been admitted twice or more. Children spent a median of nine days in hospital (IQR 3-24). The children who died from haematological cancer spent most time in hospital, as $75 \%$ had spent 14 days or more in hospital within the last 30 days of life; the median 
number of days in hospital was 28 days (IQR 15-30) within this group. Children who died from noncancerous conditions spent a median of seven days in hospital (IQR 3-15) and children with respiratory conditions had the lowest rate with a median of four days (IQR 2-11).

Children who died from non-cancerous diagnoses generally had lower odds of hospital admission (adjusted OR 0.5; 95\% CI 0.3-0.8) and of spending more than 14 days in hospital (adjusted OR 0.5; 95\% CI 0.4-0.8). However, this group appeared to have higher odds of ICU admission (adjusted OR 3.6; 95\% CI 2.3-5.6), mechanical ventilation (adjusted OR 2.9; 95\% CI 1.5-5.5) and hospital death compared to children with non-haematological cancer (adjusted OR 2.1; 95 \% CI 1.4-3.0) (Table 2).

\section{DISCUSSION}

This nationwide population-based study was among the first studies of HI-EOL in the paediatric setting to include non-cancerous decedents. One in four deaths was caused by cancer; other deaths resulted from a variety of non-cancerous diagnoses. Across diagnoses, we identified high rates of indicators of HI-EOL, especially hospital death and ICU admission. Children with solid tumours received less intensive treatment and were less likely to die in hospital compared to both children with non-cancerous conditions and haematological cancer. Children who died from haematological cancers experienced substantially higher intensity of treatment at EOL than both children with solid tumours and non-cancerous conditions.

Our finding of hospital death as the most common indicator of HI-EOL corresponds to the findings in other studies of HI-EOL among children $(5,7-10,22)$. The proportion of deaths occurring in a hospital setting however, ranged from $43 \%$ (8) to $85 \%(9)$ within these studies. Since they were restricted to children who died from cancer, the rates are not directly comparable with our findings in the Danish population.

Proportions varied between countries for each indicator of HI-EOL, and while such discrepancies may be influenced by several factors, differences in culture and health care systems are likely explanations. In general, Danish children appeared to be treated more intensively compared to Canadian and

This article is protected by copyright. All rights reserved 
American children with cancer $(7,8)$, but less intensively compared to children with cancer in Korea and Taiwan $(5,6)$.

Our results revealed that children who died from haematological cancers, were treated more intensively on any indicator of HI- EOL compared with children with solid tumours. This finding is consistent with previous cross-sectional studies investigating place of death or HI-EOL among paediatric cancer decedents $(5,8,23-25)$, presumably, this reflects that the disease trajectories are different from solid tumours, which are more predictable. Death from haematological cancer is typically more acute despite the life-threatening nature of the diagnosis, as these conditions tend to be potentially curable even at late stages (26-28).

A cross-sectional survey conducted among the bereaved parents of 114 children with complex chronic conditions other than cancer and heart failure found significant differences in the patterns of EOL treatment (22), We found, however, that non-cancerous conditions, despite a variety of diagnoses, had rather consistent rates on each intensity indicator. Only the group of cardiovascular conditions appeared to differ from the others with higher odds of ICU admission, mechanical ventilation and hospital death.

Children suffering from solid tumours appeared to have more frequent visits to hospital and spend more time in hospital at EOL compared with children with non-cancerous diagnoses in general; yet frequencies of intensive medical interventions and home death were considerably higher among noncancerous patients. These differences may be due to natural variations in disease aetiology such as shorter or less predictable illness trajectories among non-cancerous diagnoses, which can make it difficult to determine and prepare for the terminal stage $(29,30)$. However, the fact that children dying from solid tumours received less intensive treatment and were more likely to die at home despite more frequent and longer stays in hospital compared with each non-cancerous diagnosis, might also reflect a higher degree of awareness of palliative care and of the possibility of dying at home among oncologists than within other fields of paediatric care.

\section{Strengths and limitations}

This article is protected by copyright. All rights reserved 
The strength of this study lies primarily in quality of the nationwide Danish registries, which provided a unique opportunity to investigate the intensity of treatment among a complete sample of children, who died from a variety of diseases in a setting with equal and universal access to health care.

The currently most feasible approach to studying the quality of EOL care is to go back from the time of death to evaluate the care provided (19); however, this design has some limitations.

Most importantly, we did not know the intent of the care delivered, and although we have demonstrated that children were treated with high intensity at EOL, we were not able to determine whether the intensity of treatment was appropriate. We only had access to routinely collected administrative data, and thus no knowledge of neither the child's prognosis nor the family's preferences for EOL care. Furthermore, we categorised children's diagnoses based on the underlying cause of death registered on the death certificate. However, there may be multiple contributory causes of death, and the validity of this categorization depends highly on the correctness of the underlying diagnosis. Danish mortality statistics are not regularly validated and have not been validated specifically among children (18). A study did validate acute myocardial infarction in Danish mortality statistics and found a high sensitivity in the registries compared to clinical records (31).

We determined indicators of HI-EOL based on the indicators of the quality of EOL cancer care identified by Earle et al (19). These indicators were based on data from a population of adult patients with cancer; however, since no similar work has been published based on paediatric patients or patients with other life-limiting conditions than cancer, it is possible that some of these indicators of HI-EOL would not indicate poor quality of care in this particular population. Furthermore, although measures of HI-EOL are regarded as indicators of poor quality of EOL, experiencing high intensity treatment does not necessarily prove that poor care was provided, as some children die during attempts to save or prolong life and some families may prefer intensive treatment despite being wellinformed about the child's imminent death. Indicators of HI-EOL can, however, identify areas where certain patient groups differ and need to be further investigated.

Despite the limitations, this study provides important insight into the disparities in intensity of paediatric treatment at EOL according to the underlying diagnoses. Future research should address the mechanisms behind such disparities.

This article is protected by copyright. All rights reserved 


\section{CONCLUSION}

Danish paediatric patients received highly intensive treatment within the last month of life and the child's underlying diagnosis was strongly associated with the intensity of treatment. Children who died from solid tumours experienced significantly lower intensity of treatment in EOL than children with both non-cancerous conditions and haematological cancers. However, the rates of intensity indicators were quite consistent among children with non-cancerous conditions. The differences between children with solid tumours and haematological cancer are most likely due to variations in disease aetiology; this may also be the case for non-cancerous conditions. However, the lack of variation within the groups of non-cancerous diagnoses might indicate that the awareness of palliative care is higher among paediatric oncologists than within other paediatric fields.

Future research should aim to investigate which measures of HI-EOL may indicate poor quality of end-of-life, specifically among terminally ill children and should study the mechanisms behind disparities to determine appropriateness of high intensity treatment at end-of-life of children.

\section{Acknowledgements}

We highly appreciate the support from Marianne Godt Hansen, MA International Business Communication, Aarhus University Hospital, on language support for this article.

Funding: This study was supported by grants from M.L. Jørgensen and Gunnar Hansens Fond, Kong Christian den Tiendes Fond and Dagmar Marshalls Fond.

Conflict of interest: The authors have no conflicts of interest to disclose.

\section{Abbreviations:}

This article is protected by copyright. All rights reserved 
HI-EOL $=$ high intensity end-of-life treatment

$\mathrm{EOL}=$ end-of-life

$\mathrm{OR}=$ Odds Ratio

$\mathrm{CI}=$ Confidence Interval

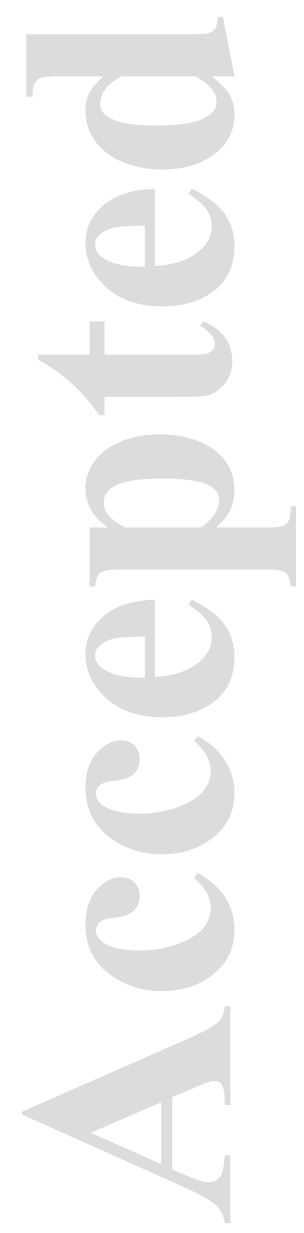

This article is protected by copyright. All rights reserved 


\section{REFERENCES}

1. Snaman JM, Kaye EC, Baker JN, Wolfe J. Pediatric palliative oncology. Curr Opin Pediatr. 2018 Feb 1;30(1):40-8.

2. Heath JA, Clarke NE, Donath SM, McCarthy M, Anderson VA, Wolfe J. Symptoms and suffering at the end of life in children with cancer: an Australian perspective. Med J Aust. 2010 Jan 18;192(2):71-5.

3. Luta X, Maessen M, Egger M, Stuck AE, Goodman D, Clough-Gorr KM. Measuring Intensity of End of Life Care: A Systematic Review. Dal Pizzol F, editor. PLoS One. 2015 Apr 14;10(4):e0123764.

4. Earle CC, Landrum MB, Souza JM, Neville BA, Weeks JC, Ayanian JZ. Aggressiveness of Cancer Care Near the End of Life: Is It a Quality-of-Care Issue? J Clin Oncol. 2008 Aug;26(23):3860-6.

5. Hung Y-N, Liu T-W, Lin D-T, Chen Y-C, Chen J-S, Tang ST. Receipt of Life-Sustaining Treatments for Taiwanese Pediatric Patients Who Died of Cancer in 2001 to 2010: A Retrospective Cohort Study. Medicine (Baltimore). 2016 Apr;95(16):e3461.

6. Park JD, Kang HJ, Kim YA, Jo M, Lee ES, Shin HY, et al. Trends in the aggressiveness of end-of-life care for Korean pediatric cancer patients who died in 2007-2010. Glod JW, editor. PLoS One. 2014 Jun 12;9(6):e99888.

7. Johnston EE, Alvarez E, Saynina O, Sanders L, Bhatia S, Chamberlain LJ. Disparities in the Intensity of End-of-Life Care for Children With Cancer. Pediatrics. 2017 Oct 28;140(4):e20170671.

8. Kassam A, Sutradhar R, Widger K, Rapoport A, Pole JD, Nelson K, et al. Predictors of and trends in high-intensity end-of-life care among children with cancer: A population-based study using health services data. J Clin Oncol. 2017;35(2):236-42.

9. Revon-Rivière G, Pauly V, Baumstarck K, Bernard C, André N, Gentet J, et al. High-intensity end-of-life care among children, adolescents, and young adults with cancer who die in the

This article is protected by copyright. All rights reserved 
hospital: A population-based study from the French national hospital database. Cancer. 2019 Mar;cncr.32035.

10. Tzuh Tang S, Hung Y-N, Liu T-W, Lin D-T, Chen Y-C, Wu S-C, et al. Pediatric end-of-life care for Taiwanese children who died as a result of cancer from 2001 through 2006. J Clin Oncol. 2011 Mar 1;29(7):890-4.

11. Ananth P, Melvin P, Feudtner C, Wolfe J, Berry JG. Hospital Use in the Last Year of Life for Children With Life-Threatening Complex Chronic Conditions. Pediatrics. 2015 Nov 1;136(5):938-46.

12. Johnston EE, Bogetz J, Saynina O, Chamberlain LJ, Bhatia S, Sanders L. Disparities in Inpatient Intensity of End-of-Life Care for Complex Chronic Conditions.

13. Wolff SL, Christiansen CF, Nielsen MK, Johnsen SP, Schroeder H, Neergaard MA. Predictors for place of death among children:A systematic review and meta-analyses of recent literature. Vol. 179, European Journal of Pediatrics. Springer; 2020. p. 1227-38.

14. Statistics Denmark. Population and population projections - Statistics Denmark [Internet]. [cited 2019 Jan 3]. Available from: https://www.dst.dk/en/Statistik/emner/befolkning-ogvalg/befolkning-og-befolkningsfremskrivning

15. Health TDM of. Healthcare in Denmark - an overview. Indenrigs- og Sundhedsministeriet;

16. Raunkiaer M. Lukashuset En 1 års evaluering.

17. Danish national board of health. Evaluering af de fem hospitalsbaserede regionale teams.

18. Helweg-Larsen K. The Danish Register of Causes of Death. Scand J Public Health. 2011;39(7 Suppl):26-9.

19. Earle CC, Park ER, Lai B, Weeks JC, Ayanian JZ, Block S. Identifying potential indicators of the quality of end-of-life cancer care from administrative data. J Clin Oncol. 2003 Mar 15;21(6):1133-8.

20. Tang ST, Wu S-C, Hung Y-N, Huang E-W, Chen J-S, Liu T-W. Trends in quality of end-of-

This article is protected by copyright. All rights reserved 
life care for Taiwanese cancer patients who died in 2000-2006. Ann Oncol. 2009 Feb;20(2):343-8.

21. Park JD, Kang HJ, Kim YA, Jo M, Lee ES, Shin HY, et al. Trends in the aggressiveness of end-of-life care for Korean pediatric cancer patients who died in 2007-2010. Glod JW, editor. PLoS One. 2014 Jun;9(6):e99888.

22. Decourcey DD, Silverman M, Oladunjoye A, Balkin EM, Wolfe J. Patterns of Care at the End of Life for Children and Young Adults with Life-Threatening Complex Chronic Conditions. J Pediatr. 2017;193:196-203.e2.

23. Håkanson C, Öhlén J, Kreicbergs U, Cardenas-Turanzas M, Wilson DM, Loucka M, et al. Place of death of children with complex chronic conditions: cross-national study of 11 countries. Eur J Pediatr. 2017 Mar 9;176(3):327-35.

24. Gao W, Verne J, Peacock J, Stiller C, Wells C, Greenough A, et al. Place of death in children and young people with cancer and implications for end of life care: a population-based study in England, 1993-2014. BMC Cancer. 2016 Dec 19;16(1):727.

25. Shah A, Diggens N, Stiller C, Murphy D, Passmore J, Murphy MFG. Place of death and hospital care for children who died of cancer in England, 1999-2006. Eur J Cancer. 2011;47(14):2175-81.

26. Gatta G, Capocaccia R, Stiller C, Kaatsch P, Berrino F, Terenziani M. Childhood cancer survival trends in Europe: A EUROCARE working group study. J Clin Oncol. 2005 Sep $21 ; 23(16): 3742-51$.

27. Kaatsch P. Epidemiology of childhood cancer. Vol. 36, Cancer Treatment Reviews. W.B. Saunders; 2010. p. 277-85.

28. Cohen J, Beernaert K, Van den Block L, Morin L, Hunt K, Miccinesi G, et al. Differences in place of death between lung cancer and COPD patients: a 14-country study using death certificate data. NPJ Prim care Respir Med. 2017 Dec 3;27(1):14.

29. Bostwick D, Wolf S, Samsa G, Bull J, Taylor DH, Johnson KS, et al. Comparing the Palliative 
Care Needs of Those With Cancer to Those With Common Non-Cancer Serious Illness. 2017;

30. Siden H, Miller M, Straatman L, Omesi L, Tucker T, Collins JJ. A report on location of death in paediatric palliative care between home, hospice and hospital. Palliat Med. 2008 Oct $28 ; 22(7): 831-4$.

31. Madsen M, Davidsen M, Rasmussen S, Abildstrom SZ, Osler M. The validity of the diagnosis of acute myocardial infarction in routine statistics: A comparison of mortality and hospital discharge data with the Danish MONICA registry. J Clin Epidemiol. 2003 Feb 1;56(2):124-30.

This article is protected by copyright. All rights reserved 


\section{Table 1: Characteristics of the study population according to underlying cause of death in the three main groups and}

\section{for subgroups of non-cancerous conditions.}

\begin{tabular}{|c|c|c|c|c|c|c|c|c|c|c|c|}
\hline 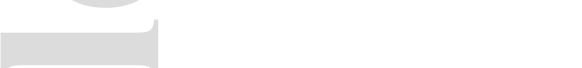 & & \multicolumn{3}{|c|}{ Underlying cause of death } & \multicolumn{7}{|c|}{ Non-cancerous conditions } \\
\hline 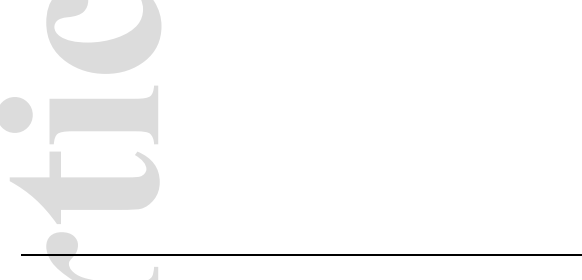 & & 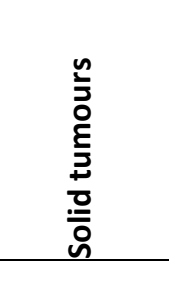 & 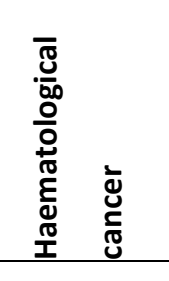 & 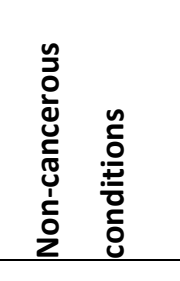 & 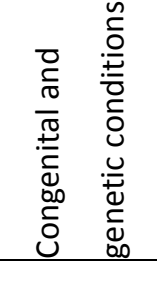 & 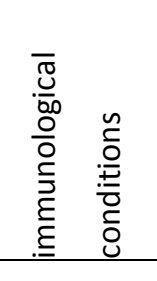 & 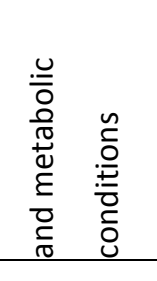 & 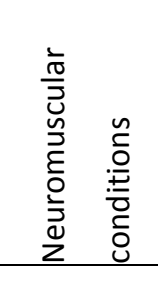 & 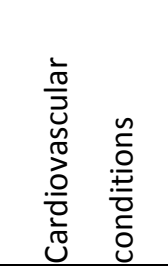 & 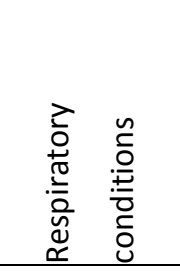 & 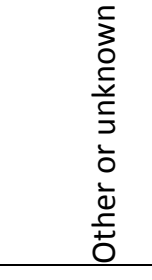 \\
\hline Total & 938 & 162 & 80 & 696 & 152 & 68 & 75 & 165 & 64 & 55 & 117 \\
\hline \multicolumn{12}{|l|}{ Age at death } \\
\hline $1-4$ years, $n(\%)$ & $374(39.8)$ & $38(23.5)$ & $34(42.5)$ & $302(43.4)$ & $82(54.0)$ & $36(52.9)$ & $45(60.0)$ & $55(33.3)$ & $14(21.9)$ & $25(45.5)$ & $45(38.5)$ \\
\hline 5-9 years, $n(\%)$ & 149 (15.9) & $37(22.8)$ & $13(16.3)$ & $99(14.2)$ & $25(16.5)$ & $7(10.3)$ & $8(10.7)$ & $28(17.0)$ & $8(12.5)$ & $7(12.7)$ & $16(13.7)$ \\
\hline 10-13 years, n(\%) & $157(16.7)$ & $42(25.9)$ & $13(16.3)$ & $102(14.7)$ & $15(9.9)$ & $7(10.3)$ & $10(13.3)$ & $29(17.6)$ & $17(26.6$ & $8(14.55)$ & $16(13.7)$ \\
\hline 14-17 years, n(\%) & $259(27.6)$ & $45(27.8)$ & $20(25.0)$ & $193(27.7)$ & $30(19.7)$ & $18(26.5)$ & $12(16.0)$ & $53(32.1)$ & $25(39.1)$ & $15(27.3)$ & $40(34.2)$ \\
\hline 1. median age at death (IIR) & $\begin{array}{c}8.5 \\
(3.1-14.4)\end{array}$ & $\begin{array}{c}10.9 \\
(6.1-14.4)\end{array}$ & $\begin{array}{c}7.5 \\
(4.1-13.8)\end{array}$ & $\begin{array}{c}7.7 \\
(2.5-14.5)\end{array}$ & $\begin{array}{c}5.3 \\
(2.4-12.4)\end{array}$ & $\begin{array}{c}4.5 \\
(1.5-14.9)\end{array}$ & $\left.\begin{array}{c}3.8 \\
(2.3-11.1)\end{array}\right)$ & $\begin{array}{c}10.0 \\
(3.7-15.1)\end{array}$ & $\begin{array}{c}12.7 \\
(6.6-15.8)\end{array}$ & $\begin{array}{c}6.5 \\
(2.2-14.5)\end{array}$ & $\begin{array}{c}9.6 \\
(2.5-15.5)\end{array}$ \\
\hline Gender & & & & & & & & & & & \\
\hline Male, $n(\%)$ & $510(54.8)$ & $76(47.5)$ & $42(52.5)$ & $392(56.7)$ & $90(59.2)$ & 38 (55.9) & $46(61.3)$ & $80(48.8)$ & $34(53.1)$ & $32(58.2)$ & $72(63.7)$ \\
\hline$e^{\text {Female, n(\%) }}$ & $421(45.2)$ & $84(52.5)$ & $38(47.5)$ & $299(43.3)$ & $62(40.8)$ & $30(44.1)$ & $29(38.7)$ & $84(51.2)$ & $30(46.9)$ & $23(41.8)$ & $41(36.3)$ \\
\hline
\end{tabular}




\begin{tabular}{|c|c|c|c|c|c|c|c|c|c|c|c|}
\hline Hospital admission* $\geq 2, n(\%)$ & $285(30.4)$ & $86(53.1)$ & $34(42.5)$ & $165(23.7)$ & $35(13.3)$ & $8(11.8)$ & $24(32.0)$ & $43(26.1)$ & $13(20.3)$ & $13(23.6)$ & $29(24.8)$ \\
\hline median no. of admissions* (IQR) & $1.0(1-2)$ & $2.0(1-4)$ & $1.0(1-3)$ & $1.0(1-2)$ & $1.0(1-2)$ & $1.0(1-1)$ & $1.0(1-2)$ & $1.0(1-2)$ & $1.0(1-2)$ & $1.0(1-2)$ & $1.0(1-2)$ \\
\hline Days of hospital admission* $\geq 14, n(\%)$ & $257(27.4)$ & $54(33.3)$ & $60(75.0)$ & $143(50.6)$ & $32(21.1)$ & $18(26.5)$ & $18(24.0)$ & $32(19.4)$ & $10(15.6)$ & $6(10.9)$ & $27(23.1)$ \\
\hline median no. of days* (IQR) & $9.0(3-24)$ & $11.0(6-18)$ & $28.0(15-30)$ & $7.0(2.5-15)$ & $5.0(3-17)$ & $6.5(2-29)$ & $9.0(4-14)$ & $6.0(3-15)$ & $5.0(2-10)$ & $4.0(2-11)$ & $8.0(3-24)$ \\
\hline ICU admission*, n(\%) & $315(38.6)$ & $29(18.4)$ & $46(58.2)$ & $240(41.4)$ & 44 (33.9) & $26(56.5)$ & $21(30.0)$ & $61(41.5)$ & $31(56.4)$ & $17(40.5)$ & $40(44.4)$ \\
\hline Mechanical ventilation*, n(\%) & $253(27.0)$ & $18(11.1)$ & $39(48.8)$ & $196(28.2)$ & $36(23.7)$ & $24(35.3)$ & $18(24.0)$ & $49(29.7)$ & $28(43.8)$ & $16(29.1)$ & $25(21.4)$ \\
\hline Hospital death, $\mathrm{n}(\%)$ & $704(75.1)$ & $101(65.4)$ & $66(82.5)$ & $537(77.2)$ & $115(75.7)$ & $53(77.9)$ & $60(80.0)$ & $119(72.1)$ & 55 (85.9) & $45(81.8)$ & 90 (76.9) \\
\hline \multicolumn{12}{|l|}{ Number of indicators of HI-EOL } \\
\hline$\geq 1, n(\%)$ & $722(77.0)$ & $110(67.9)$ & $70(87.5)$ & 542 (77.9) & $116(76.3)$ & $53(78.0)$ & $60(80.0)$ & $120(72.7)$ & $56(87.5)$ & $45(81.8)$ & 92 (78.6) \\
\hline$\geq 2, n(\%)$ & $433(46.2)$ & $67(41.4)$ & $61(76.3)$ & $305(43.8)$ & 61 (40.1) & 33 (48.5) & 73 (44.2) & 73 (44.3) & $34(53.1)$ & $20(36.4)$ & 51 (43.6) \\
\hline$\geq 3, n(\%)$ & $274(29.2)$ & $20(12.3)$ & $47(58.75)$ & $207(29.74$ & $37(24.3)$ & 24 (35.3) & $17(22.7)$ & $54(32.7)$ & $29(45.3)$ & $16(29.1)$ & $30(25.6)$ \\
\hline
\end{tabular}

$\mathrm{IQR}=$ inter-quartile range

$*$ : In the last month of life

This article is protected by copyright. All rights reserved 


\section{Table 2: Adjusted odds ratios ${ }^{1}$ for receiving indicators of $\mathrm{HI}-\mathrm{EOL}$}

\section{Underlying cause of death}

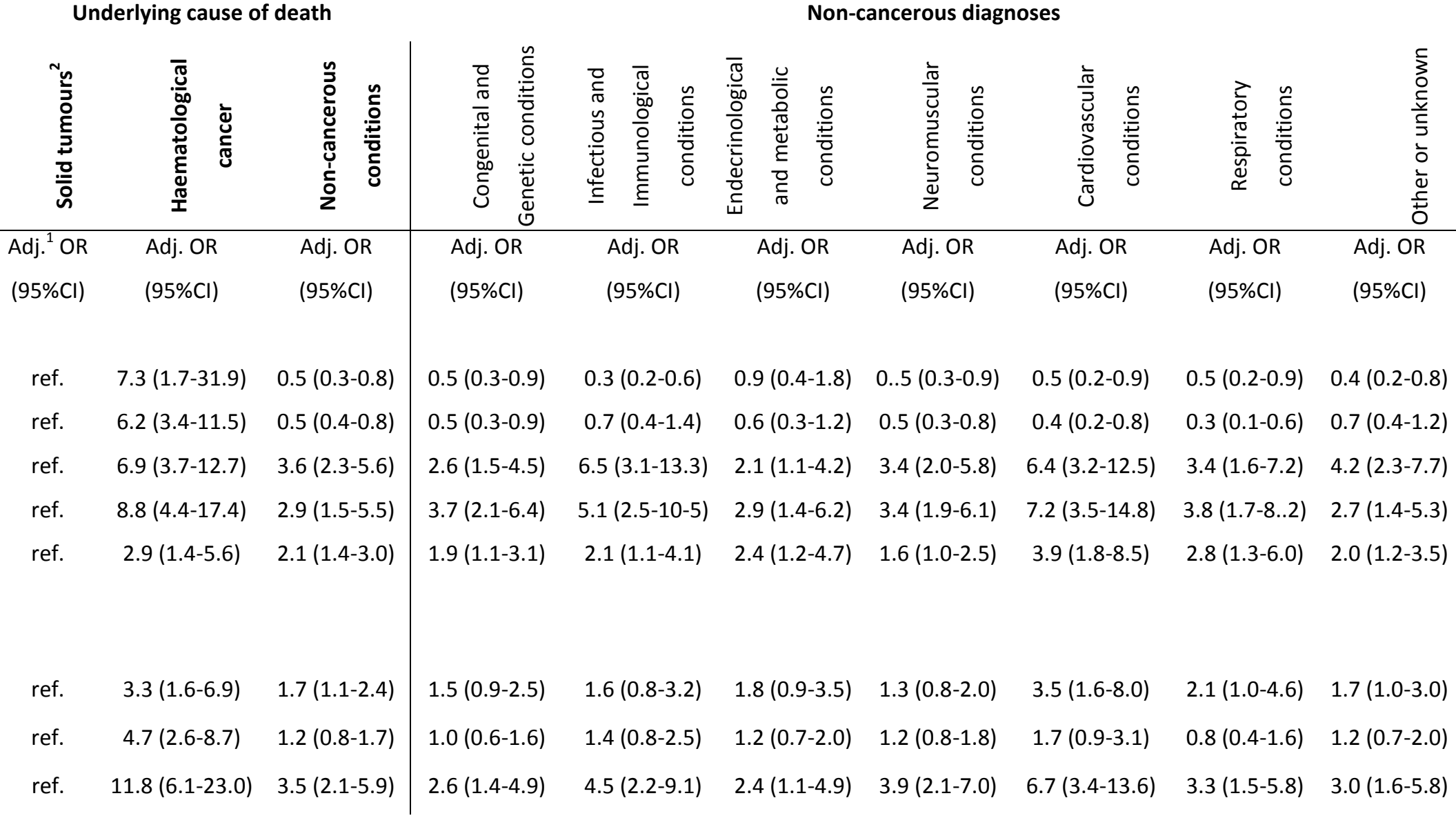

\section{Indicators of HI-EOL}

Hospital admission $\geq 2$

Days of hospital admission $\geq 14$

ICU admission

Mechanical ventilation

Hospital death

Number of intensity indicators 1

\section{2}

3

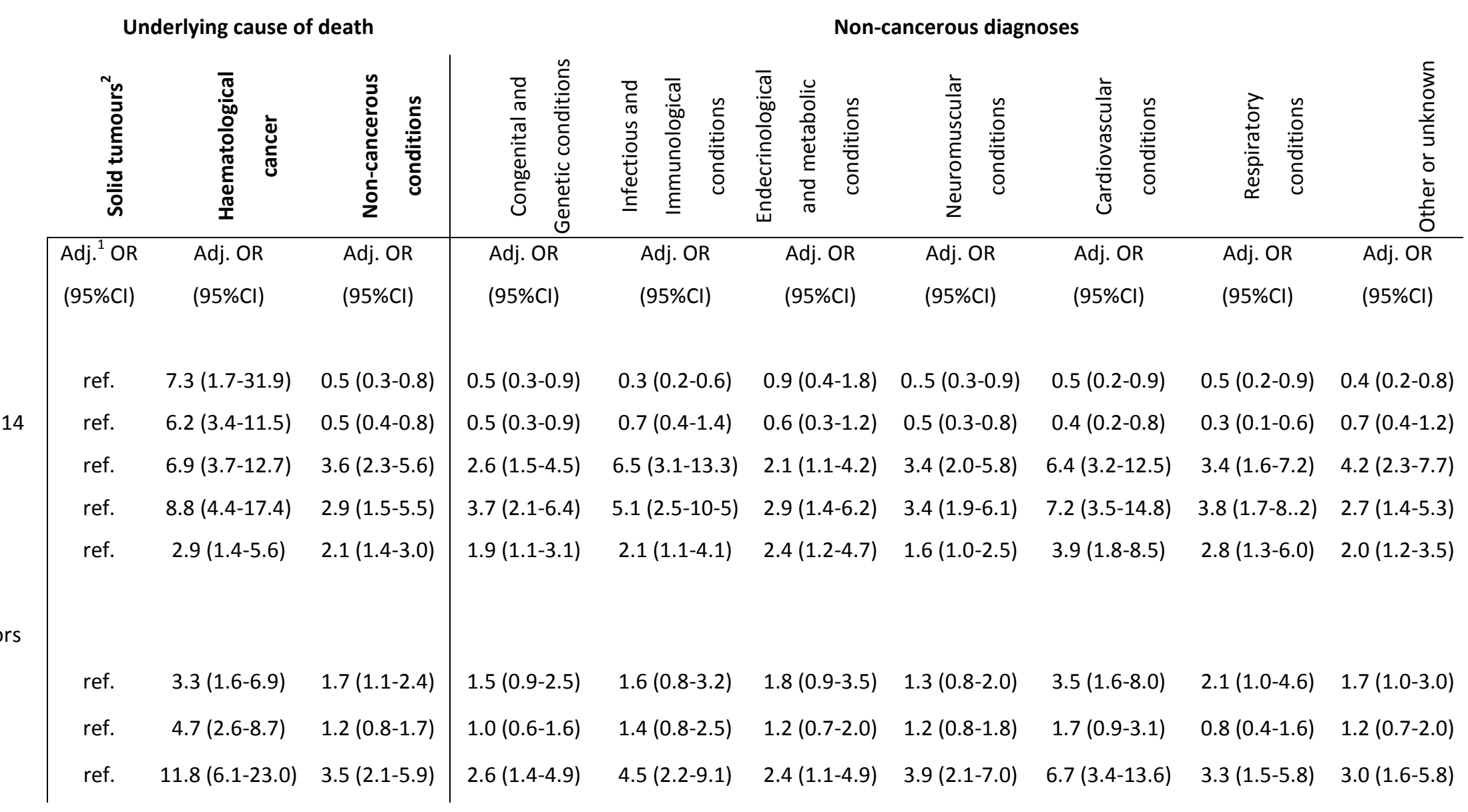

1: Adj.: adjusted for year of death, age at death and gender (multivariable analysis did not change any conclusions from the crude analysis)

2: ref. = reference group

This article is protected by copyright. All rights reserved 
Figure 1: Distribution of underlying causes of paediatric death (\%)

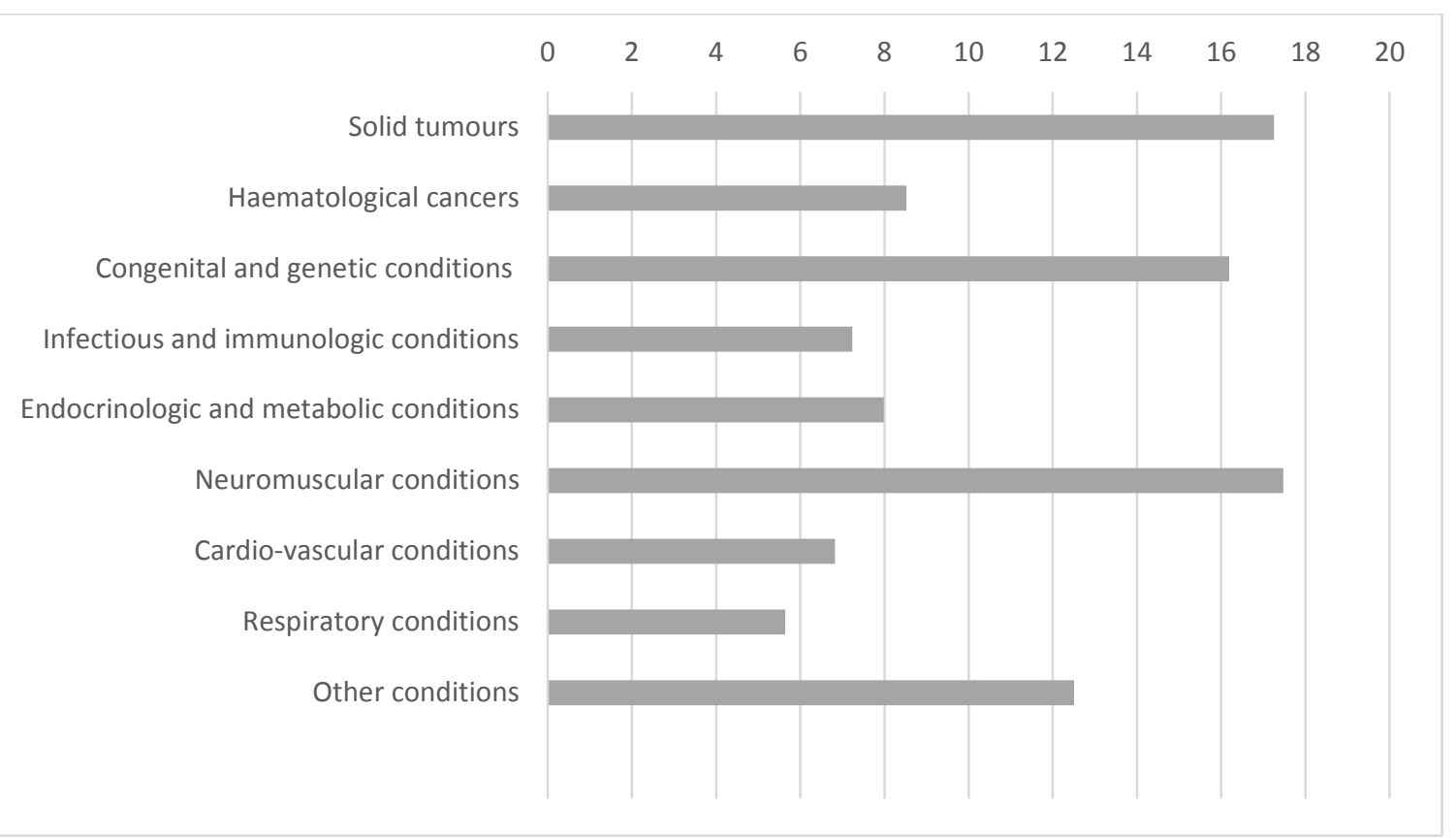

